\title{
Seismic performance for a concrete school building designed before the building standard act revised
}

\author{
Tetsuya Ohmura, Mamoru Kawasaki
}

\begin{abstract}
This paper described the seismic performance of a concrete school building built in 1973, and numerous similar school buildings are being used even now in not only local area but also urban area in Japan.
\end{abstract}

The Japanese building standard act was revised in 1981 considered non-linearity. However, a number of buildings built before 1981 are existing, seismic evaluations for those building have actively been assessed based on the seismic evaluation standard $^{1)}$ published by The Japan Building Disaster Prevention Association after especially 1995 Kobe Earthquake.

In practical seismic evaluation works, it is relatively simple and easy to make models of general buildings, but unconventional frames are complex such as a staircase or a frame with level different girders.

The flexible length of the column with a wall having an opening or level different girders are generally assumed as the inside measurement height. The modeling way would be simply, however, the seismic behavior of the unconventional column and the building has not been confirmed yet in any study.

In this paper, non-linear three dimensional frame analyses were performed, and their results were examined. Finally, the model with seismic slits was compared with one having no seismic slits for seismic performance.

Keywords-seismic performance, dynamic analysis, concrete building, short column, level diferent girder

\section{Introduction}

The Japanese building standard act was revised in 1981 considered non-linearity. However, a number of buildings built before 1981 are existing, seismic evaluations for those buildings have actively been assessed based on the Seismic Evaluation Standard ${ }^{1)}$ published by The Japan Building Disaster Prevention Association after especially 1995 Kobe Earthquake. This standard takes the strength and ductility into account and defines three grades of seismic assessments to evaluate the seismic index. The modeling for columns and walls is extremely important in particularly the second and third grade of the seismic evaluation often taken, because the girders are assumed as rigid, and the strength and ductility of columns and walls directly influence on the seismic index.

This standard also corresponds to diversified buildings. However, for a frame of such as a staircase with girders located mid-story, the modeling concept depends on a judgment by an engineer.

Tetsuya Ohmura , Mamoru Kawasaki

Tokyo City University

Japan
In practical seismic evaluation works, it is relatively simple and easy to make models of general buildings, but when dealing with unconventional frames such as staircases or a frame with different level girders as mentioned above, it is much more complex.

First of all, the ratio of opening for a perforated wall should be calculated based on the standard. The ration of openings is defined as the square root of the openings area divided by the wall area.

A perforated concrete wall is modeled as a shear wall, if the opening ratio is 0.4 and less. On the other hand, one with more than the opening ratio of 0.4 is modeled as a column with a wing wall.

In addition, the flexible length of the column with a wall having an opening or level different girders are generally assumed as the inside measurement height. The modeling way would be simply, however, the seismic behavior of the column and the building has not been confirmed yet in any study.

The modeling concept is simplified to smoothly assess the seismic performance of a building even though it is not confirmed to be suited to their actual behavior. However, in order to secure the flexible length for seismic improvement, a seismic slit is often located at the edge of a column or a window in a practical seismic improvement work.

In this paper, an actual frame with a perforated wall located at staircase having short brittle columns was modeled and static and dynamic non-linear three dimensional frame analyses were performed. To be compared with the original model, also a models with seismic slits mentioned above were analyzed.

\section{Frame Property}

Fig.1, 2 and 3 show the plan, the elevation, and the member section in a three-story concrete school building built in 1973. The building had the longitudinal length of $58 \mathrm{~m}$, the span of about $17 \mathrm{~m}$ and the height of $11.5 \mathrm{~m}$. The staircase were located at the northwest and northeast side of the building.

The seismic index of $1 \mathrm{st}$, 2nd and 3rd story was respectively $0.53,0.40,0.84$ in the longitudinal direction, and more than 1.0 in every story in the span direction.

The building was damaged by the 3.11 earthquake. One of the remarkable cracking condition is shown in Figure 2. The crack width without any note was $0.3 \mathrm{~mm}$. Diagonal cracks were observed at around the edge of openings.

The concrete strength of $17.5,16.0,14.5 \mathrm{~N} / \mathrm{mm}^{2}$ was measured at $1 \mathrm{st}, 2 \mathrm{nd}$, 3rd floor respectively in the building 


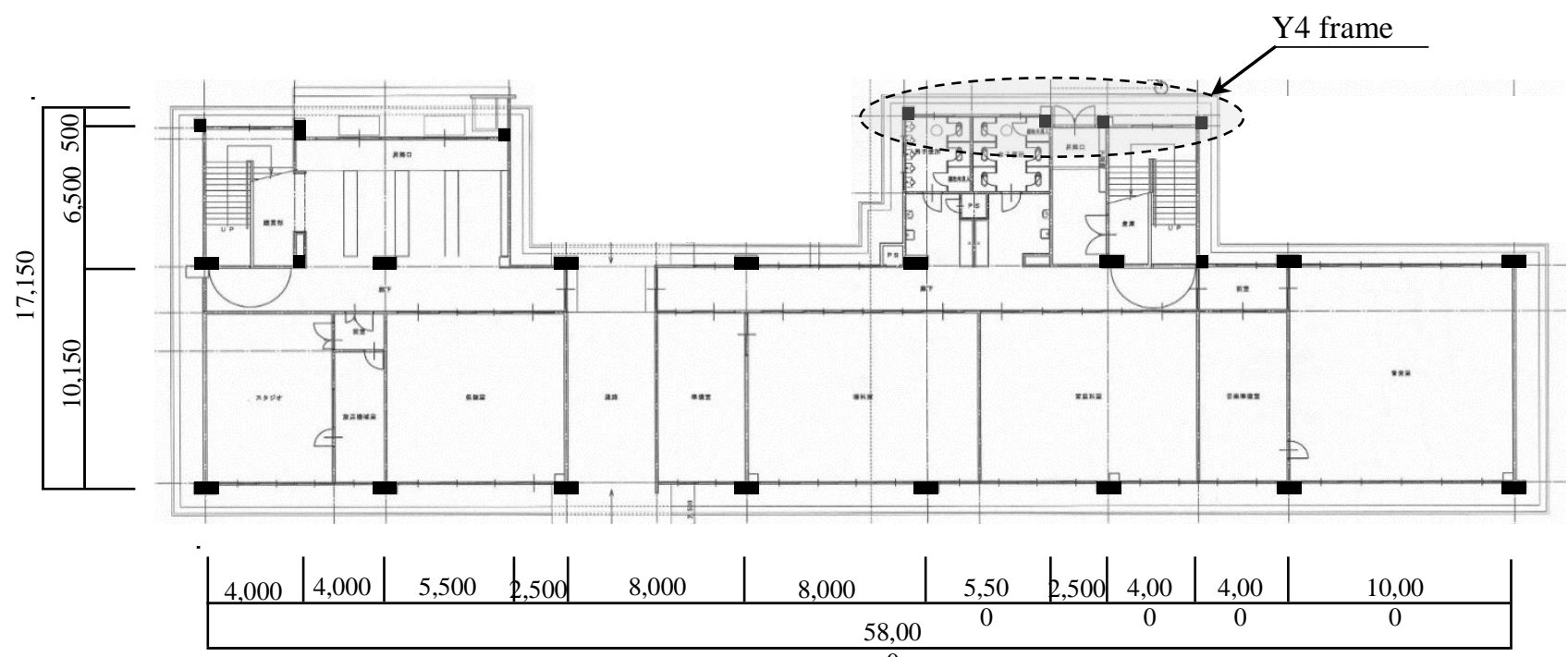

Figure 1 Plan (unit: $\mathrm{mm}$ )

based on the material test. the yield strength of $343 \mathrm{~N} / \mathrm{mm}^{2}$ for the longitudinal rebar and of $294 \mathrm{~N} / \mathrm{mm}^{2}$ for the hoop, stirrup and wall rebar were assumed.

Figure 3 shows the column and the girder section. The main column had the section of $500 \mathrm{~mm}$ square. And the main girder G1 had the depth of $900 \mathrm{~mm}$ and the width of $300 \mathrm{~mm}$. The wall had $120 \mathrm{~mm}$ of thickness and longitudinal and transverse rebar of $9 \mathrm{~mm}$ with $200 \mathrm{~mm}$ space.

\section{Analysis}

The building was modeled as a moment resist frame composed of non-linear members with multi-spring / moment spring and shear spring for a column and a girder respectively as shown Figure 6. Shear wall was modeled as a three columns model.

Two types of models were made. Model \#1 was the original model which meant the current building. Model \#2 was the model with seismic slits at the edges of the short columns around the stair case as the dash line shown in Figure 2 which meant the seismic improved building.

Three dimensional non-linear static analyses i.e. push over analyses were performed first, and three dimensional non-linear dynamic analysis next. Figure 4 and 5 show the frame model in the static analysis and the dynamic analysis respectively. Tri-linear model considering crack moment strength and shear strength was applied to the moment spring and shear spring. Takeda model was applied for the dynamic analysis. The basement was supported by pin support at every under the columns. The uplift at the basement due to lateral load was not taken into account. Lateral load distribution $\mathrm{Ai}$ and gravity load of $12 \mathrm{kN} / \mathrm{m}^{2}$ were defined based on Japanese building standard act.

The model for dynamic analysis were made based on the static analyses results as modified Takeda model. Figure 7 shows the acceleration response spectra for the earthquake motion input. Five earthquake motions were input in the longitudinal direction. Their phases for the target spectra by BRI were based on El Centro NS (1940), Hachinohe NS (1968), JMA Kobe NS (1995), Taft EW (1952), and an artificial earthquake wave (BCJ-L2).
The target spectra were the acceleration response spectra, BRI-L2, which are represented by the horizontal motion normalized response spectra times the response equivalent ratio of the damping.

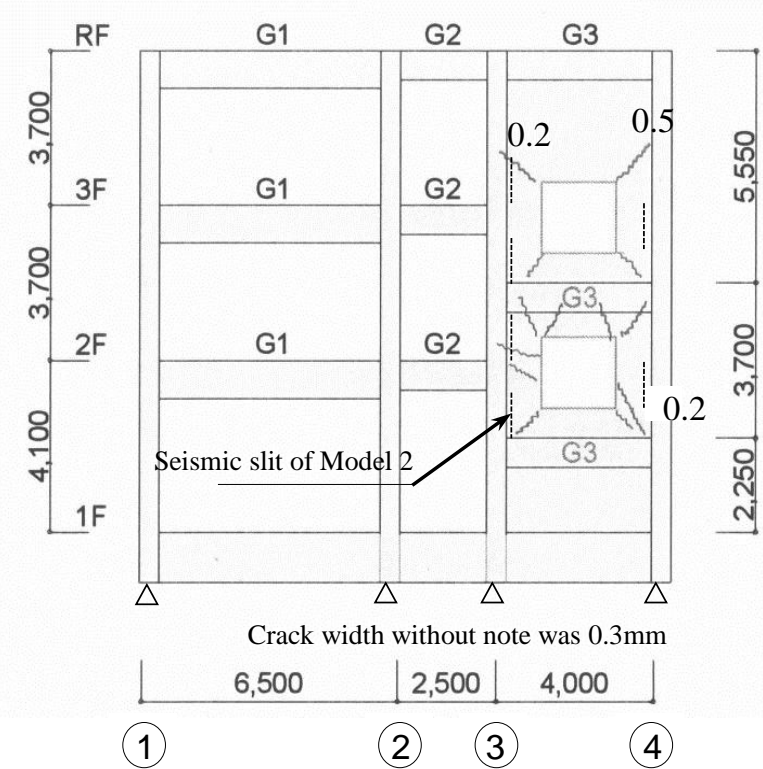

Figure 2 Elevation and the damage at 3.11 (Y4frame)

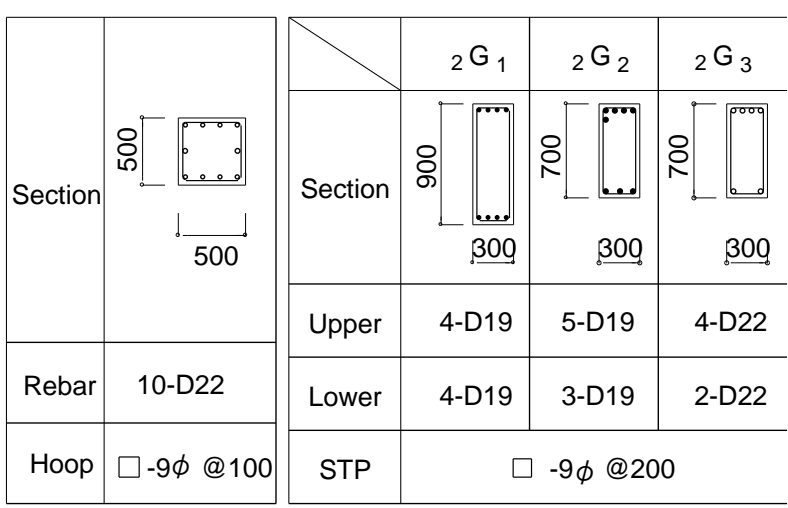

Figure 3 Column and girder 


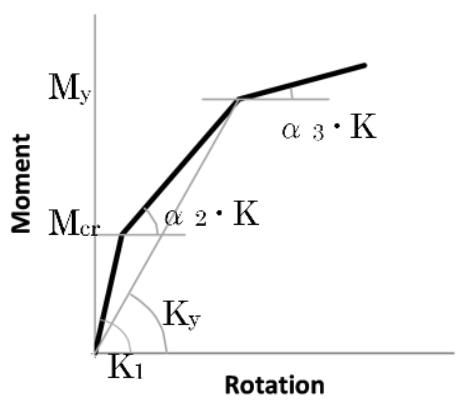

(a)

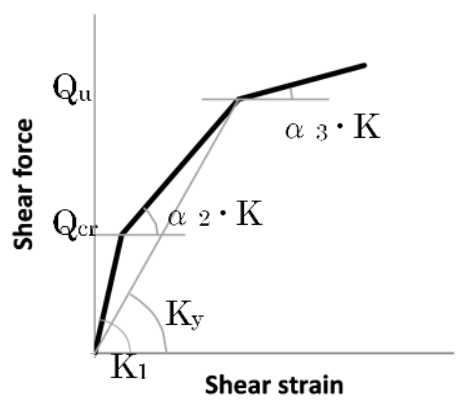

(b)

Figure 4 Hysteresis characteristics

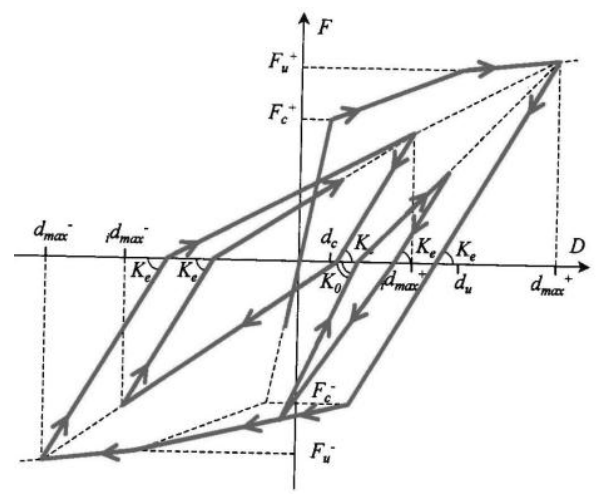

Figure 5 Cyclic model (Takeda model)

\section{Iv. Story Shear Force Versus Story Drift}

Figure 8 shows the relationship between story shear force and story drift of Model \#2. The maximum base shear coefficient of the current building of Model \#1 was 0.3 , when the tolerance in the push over analysis became too large, because of short brittle columns. On the other hand, the maximum base shear coefficient of the building with seismic slit of Model \#2 was 0.6, when the second story drift was reached to $1 \%$, because the ductility of the columns were improved by seismic slits located at short brittle columns.

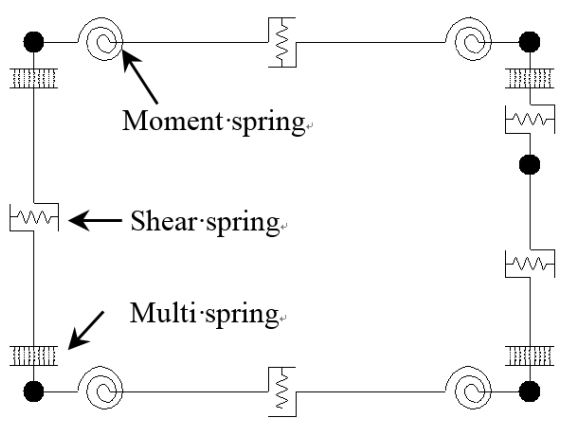

Figure 6 Model

The maximum base shear coefficient of Model \#2 became larger than one of Model \#1, and the effect of the seismic slits was proved, if they were properly located at the short brittle columns.

\section{v. Collapse Mechanism in the Static Analyses}

Figure 9 and 10 show the collapse mechanism of Y4 frame in push over analyses of the Model \#1 and \#2. The square and circle mark mean shear failure and moment hinge respectively. Shear failure was observed when the base shear coefficient was 0.1 in Model 1. The shear failure of several short brittle columns caused the inequivalent force and made the tolerance larger. In addition, it meant that the current building should be unstable even at base shear coefficient of 0.1 lower than Design Basis Earthquake (DBE) of 0.2 due to have several brittle columns.

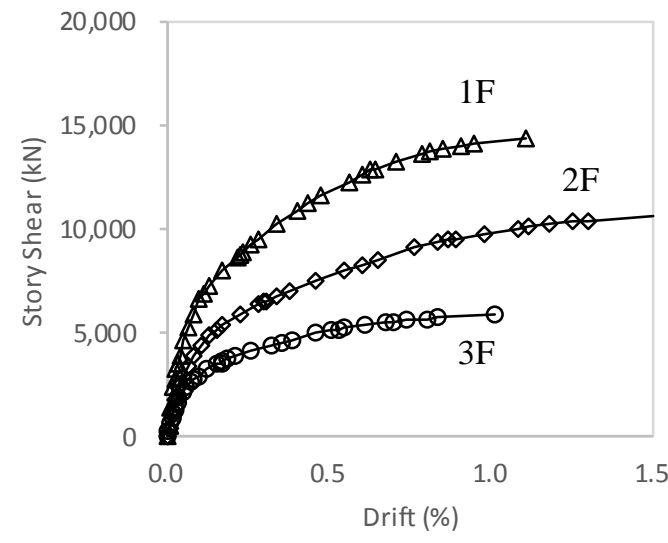

Figure 8 Hysteresis curve (Model 2)

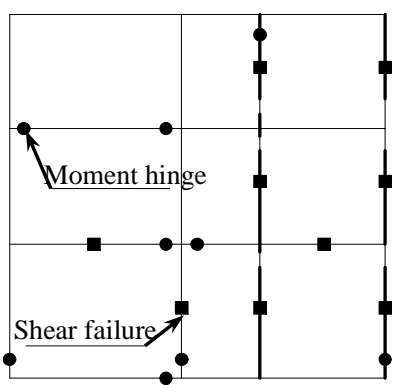

Figure 9 Hinge diagram (Model 1)

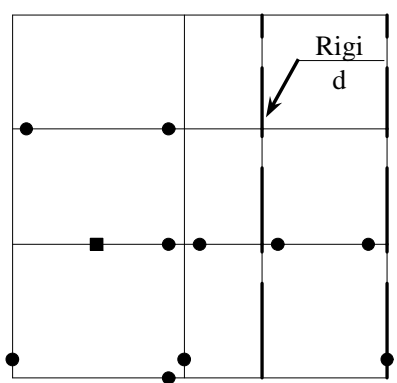

Figure 10 Hinge diagram (Model 2) 
However, shear failure was not observed in columns even at the base shear coefficient of 0.6 in Model \#2. Because the ductility of the short brittle columns was improved due to seismic slits as mentioned above, axial force resist ability of columns became better in Model \#2 than in Model \#1, as shown collapse mechanism.

\section{vi. Maximum Response acceleration, coefficient and velocity}

In this and following chapters, the dynamic analysis was performed just for Model \#2. It was hard to perform dynamic analysis for Model \#1, because Model \#1 had a vulnerable and unstable columns in the frame Y4 even in the static analysis.

Figure 11 shows the earthquake motion of the phase El Centro and the response acceleration at the first floor. The analysis time of time history response analysis were 120 second for the artificial earthquake wave (BCJ-L2), and 30 second for the other waves. The PGA was $4790 \mathrm{~mm} / \mathrm{sec}^{2}$ for the wave phase El Centro. The maximum response acceleration at the first floor was $5856 \mathrm{~mm} / \mathrm{sec}^{2}$.

Figure 12 and 13 show maximum response acceleration and shear coefficient respectively. The maximum response acceleration at the first floor were from 3895 to 5856 $\mathrm{mm} / \mathrm{sec}^{2}$. The maximum base shear coefficient was 0.6 in the wave phase El Centro. The maximum response acceleration at upper floor were amplified in all waves.

Figure 14 shows maximum response velocity. The maximum response velocity were from 289 to $330 \mathrm{~mm} / \mathrm{sec}$. The MIV $330 \mathrm{~mm} / \mathrm{sec}$. was observed for the wave phase JMA Kobe.

\section{Conclusion}

An actual frame with a perforated wall located at staircase having short brittle columns was modeled and frame analyses were performed. To be compared with the original model, also a seismic improved model with seismic slits was analyzed. We reached following conclusions.

1) The seismic slits were effective to prevent from vulnerable failure of short brittle columns.

2) The ductility should be improved for old buildings built before the building standard revised like this building to resist MCE.

\section{References}

[1] Japan Building Disaster Prevention Association (2001), Seismic Evaluation Standard and Commentary for Existing Concrete buildings

[2] Ryota Ishii, Tetsuya Ohmura : A STUDY FOR SEISMIC IMPROVEMENT OF CONCRETE FRAME WITH PERFORATED WALLS, GEOMATE, C3051，pp548-552，2015

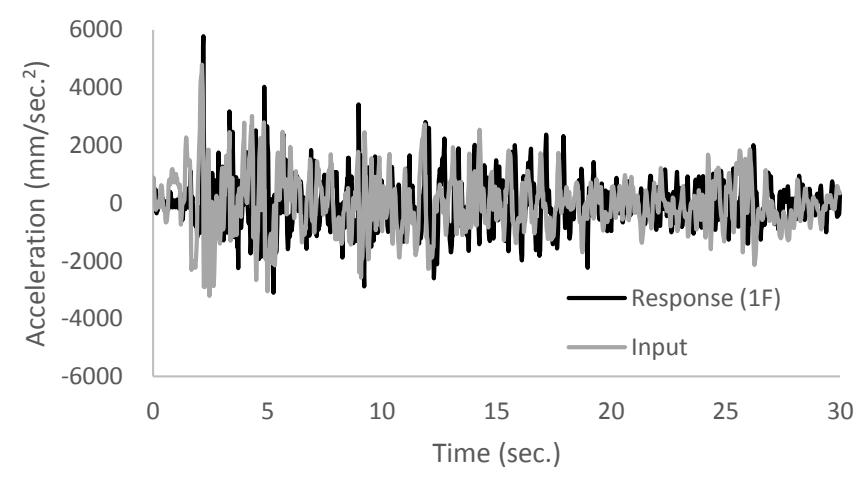

Figure 11 Time history acceleration (Phase El Centro)

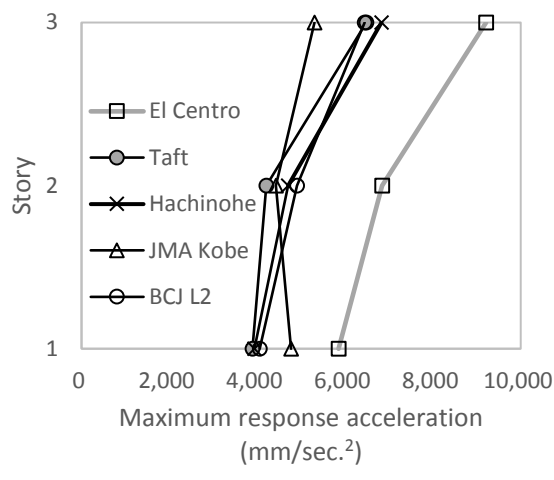

Figure 12 Maximum response acceleration

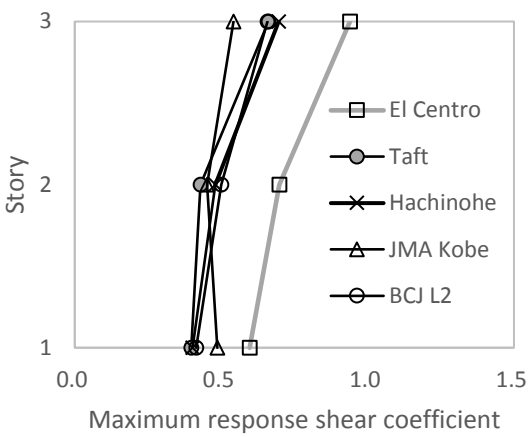

Figure 13 Maximum response shear coefficient

\section{vII. Maximum response drift}

Figure 15 shows maximum response drift. The maximum response drift were $1.26 \%$ at the second floor for the wave BCJ L2. The maximum response drift were approximately $1.0 \%$ and less except the wave BCJ L2. The ductility should be improved by not only seismic slits but also furthermore seismic improvement for this building to control the drift in MCE.

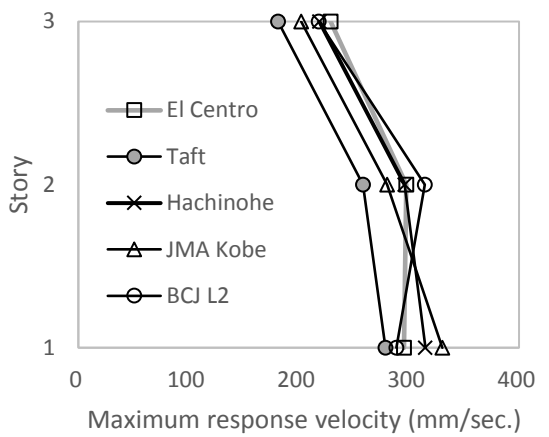

Figure 14 Maximum response velocity

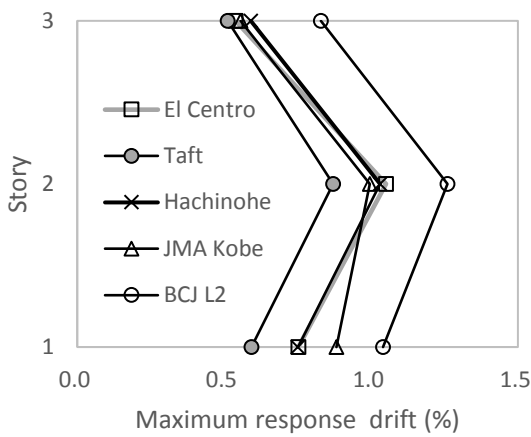

Figure 15 Maximum response drift 